\title{
On the importance of stage performance in vocal music performance
}

\author{
Ning $\operatorname{Lei}^{1, a}$ \\ ${ }^{1}$ School of music and dance, Qujing Nornal University, Yunnan, China, 655011 \\ acomsasla@163.com
}

Keywords: vocal music; stage performance; importance

Abstract. Vocal music cannot be separated from the performance of the stage, and the stage performing arts must be accompanied by national vocal music. The two promote each other and influence each other. The charm of the stage show is that it can make the theme of unwritten music art more vivid, so that the vocal music in the process of emotional expression is more abundant. The singing of stage performance can drive the emotions of the audience, helps the audience to grasp the choral singing emotion, help lead singer and audience, showing perfect help stage performing arts and singing art. Stage performance will be strident music from the simple form of singing to the development of a vivid image of the stage show, so that the vocal music becomes vivid, giving a strong vocal singing vitality.

Chinese culture has a long history, from prehistoric times to the present, has a history of thousands of years of civilization, its performance in all aspects of civilization, such as the four inventions, etc.. As a part of Chinese national art, the Chinese domestic vocal music has its unique artistic charm and cultural value [1]. With the development of society and the progress of the times, national vocal music performances with the times change, the traditional national vocal music form is single, although also pay attention to skills and singing, songs can be very vivid, most of the audience can get appreciation and praise, consistent with the public aesthetic ability, but the traditional vocal music form the lack of infectivity, unable to show the charm of the stage. Traditional national vocal music includes the Chinese national opera art and the National Opera and so on. Many of the singing skills are combined with the western domestic art to show their unique artistic charm. But if there is no singing with the stage show, there is a lack of unique charm, loss of infectivity, is not a perfect interpretation of its artistic charm, so singing should be combined with the requirements of the stage, singing must have basic singing very solid and skillful performing skills, only the perfect combination of the two the vivid artistic charm, to the national vocal show to the audience, to carry forward the forms of vocal music.

\section{The relationship between vocal music and stage performance.}

As a multi-ethnic country, China has different forms in the process of federal vocal music singing. Composed of fifty-six ethnic groups in the family, because of various ethnic customs, local customs, culture is different, in choral music singing form and expression skills also varies in different [2], these can be seen from the folk songs and performances. And the continuous development and progress in vocal music, stage performance have increasingly become the theme of the stage, with each other, it will influence each other and singing, singing the most incisive interpretation of national vocal music, from more rich and colorful.

In today's rich material life of the times, people continue to pursue spiritual satisfaction. Vocal music is a form of people's pursuit of spiritual life, and stage performances to make the vocal music more colorful. Singer should not only master the basic elements and singing skills, more important is the ability to control the stage, such as the show on the stage of the temperament, psychological quality and stage, the audience between the degree of understanding and so on. The relationship between vocal music and the stage performance is inseparable, the two as a whole, must coordinate with each other, cooperate with each other, so that the charm of vocal music is becoming more and more perfect. For a complete work, must have its corresponding background story and emotional expression, so the singer on the stage singing according to the work characteristic, combine creative background and feelings, works in concert is the vitality, become genuine and sincere. The singer in the usual practice and training, to concentrate on studying the true meaning of each work, grasp the work mood, can really understand and master works of emotion and meaning, so in singing on the 
stage to attract the audience and won the audience's approval. Stage performances are to rely on vocal music, and vocal music cannot be separated from the stage performances [3]. The vocal concert will lose part of a stage of infection, the theme and emotional expression could not even make the audience to grasp the works, but not alone on stage singing is a singer, lost momentum. While singing through stage performances, in addition to his facial expressions and emotions, to the audience of the auditory perception and visual effects on the enjoyment of beauty, make the works more vivid and true to life, causing the audience's sense of identity. Stage to grasp the sense of propriety, not rigidly adhere to the stage, can not be too exaggerated, show to put his whole heart into work, deductive works with the truth that perfect stage to infect the audience in vocal music, resonate with the audience. In short, vocal music and the stage performance influence each other, promote each other, the two inseparable [4].

\section{The importance of stage performance in vocal music.}

In the interpretation of a work, often with vocal music as the main, to stage performance as a supplement, the two complement each other, express the theme and emotion. As a form of performance art, stage performance plays a major role in vocal music performance. It promotes the development of choral music, improves the artistic form of vocal music, and promotes the progress of vocal music [5].

2.1 Stage performances can effectively reduce the burden of local singer's heart.

For many singers, the stage experience, can not bear too much pressure to sing on stage, facing the audience of tens of thousands of people, they will often because of tension caused by singing effect is poor, and in order to reach the audience and achieve satisfactory results of double stage effect, singers will choose different the way to relax the mood, for example, before entering the few roar, behind the eyes closed and so on, and the stage is one of the most effective way of [6]. Singing on the stage, the attention of the audience, the stage lights were placed on him, it will inevitably bring psychological pressure to the singer, the singer appeared stiff body and facial in Taiwan, trembling and so on, these shows singing psychological tension. While on stage too tight will lead singer mistake or forget the words out of tune in singing, bring greater psychological pressure would be serious to the singer on stage, the fear, the day after the influence of stage performance and personal development. Therefore, vocal music singers should take effective steps to relieve the tension brought by the pressure from the stage and the audience. One simple and effective way is to improve the stage performance. Stage to divert the attention of the concert, which will come from the stage and audience pressure into how vocal singing and performing perfectly, auditory and visual feast bring an audience, through singing the change of thought into the stage singing confidence [7]. Such as "the audience will not because I am not good enough and intense reaction", "the audience is not interested in singing to me", "the audience is not care about my dress" into "how to sing to attract the audience's applause and cheers", "how to inspire the audience to sing interest", this concert will be able to divert attention from the audience to the stage, performing and relaxing.

2.2 Stage performances are a way to express the emotion of vocal music singers.

There are a variety of ways to vent, some people choose to shout, some people choose to cry, some people choose to find someone to come and talk to. As a performing art, raucous music is the way to express the singer, but also the emotional expression of the singer [8]. The stage performance, as a way of expressing emotion, is often ignored by people. People often decide to sing rather than perform. However, from the effective point of view, the effect of stage performance is even better than vocal music. Because the stage performance cannot be only express emotions through body movements, but also through facial expressions to convey tenderness, so that performers in the stage of the performance of the process of natural emotion. This is for vocal music singers. In the concert to have a solid basic skills, in the performance of the stage to have superb skills. For a good work, you need to express emotions in a variety of approaches, such as sound, action, expression, etc.. In order to make the demonstrative expression more profound, simply rely on the sound is not enough, the voice of the transmission of emotion is one-sided, not deep enough. Vocal music singers should join in the stage performance when they are singing, and the visual effects and artistic feelings of the stage performances are different. The stage performance to the people's visual and auditory impact is 
enormous, it can make people realize the essence of unwritten music, deeply grasp its emotional tone. In the stage performance, the performer through the emotional expression may cause its emotion to invest, the thought is more centralized, the singing is more self-confident, causes the vocal music sings the effect to be better.

2.3Stage performances can reflect the understanding of vocal music works.

The Chinese nation is a great family with fifty-six nationalities. Among the fifty-six nationalities, each nation has its own unique national songs and singing forms. For the vocal music, every nation has its own different understanding of folk songs, sometimes it's hard to understanding embodied by the sound, and in vocal performance stage to deepen the understanding and feelings of folk songs, stage performer through stage performances of movements and facial expressions to be able to understand, understanding and expression of emotion is the perfect interpretation. The stage performance can be displayed on the stage, the stage performance is more splendid, the understanding and the understanding of the vocal music work is more profound. Through the stage performance to increase the singer's understanding and understanding of the works, so that the work can achieve the coordination of the play and sing [9]. For example, Song Zuying's classic song "into the new era", which embodies in Chinese under the leadership of the Communist Party, the new era of social Chinese ushered in the reform and opening up, the works of singing in a loud voice, full of expression, and the colorful stage will come, the beautiful scenery of the rich and populous picture, let people feel the new era the arrival of. This is the stage performance in vocal music development and progress, it allows users to see the present, look to the future.

2.4Stage performances communicate the bridge between the actor and the audience.

Since it is the process of art, there must be an audience. For vocal music, the audience is the audience. Therefore, the quality of the work is not determined by the vocal and stage performers, but the audience to decide. Therefore, the stage performance of the vocal music must be the audience at the center, the table must be able to attract the attention of the audience, to be recognized by the audience. The vocal foothold in the minds of the audience, because the audience is mainly shown on stage performers can not clearly understand the meaning, therefore, singing in the hearts of the audience's status declined, the audience also gradually fade in singing and in stage performances, this phenomenon is the main stage the performer not be able to communicate the content of the work to the audience, not to be able to attract the interest of the audience, the audience can not cause the heart, this situation is not conducive to the development of Chinese vocal music. So in this case, only the singer will stage the expression of meaning and theme to the audience, to the audience, in order to better development of China's vocal concert, only pay attention to the stage, careful interpretation of the understanding of the work, in order to build a bridge between the actors and the audience in [10]. If just rely on the way of singing to the audience to convey emotion, may not leave a deep impression on the audience, even in the understanding of the work on the deviation, which would give vocal music has a significant adverse effect. The deviation of the understanding of the work will make the audience's understanding of the deviation of vocal music singing, resulting in loss of interest in choral music singing, the development and progress of vocal music. Therefore, the vocal music singer in singing works to strengthen the stage performance improvement, the importance of the stage in the practice process, practice training and strengthening stage of excellent works, attracted the attention of the audience from the visual, auditory deterrent from the audience's ears.

\section{Conclusion}

The stage performance is very important in the performance of vocal music. It is not only the bridge between the audience and the singer, but also the premise of the development and progress of Chinese vocal music. The vocal music singer must combine the vocal music performance and the stage performance, the singer through the stage performance, the understanding and the understanding of the work will demonstrate to the audience, causes the audience to the sympathetic chord. The audience has a new understanding and understanding of choral music performance, more conducive to the development of vocal music combined with progress. Unwritten music singers should pay attention to the stage performance, through the efforts to make vocal music to a new level. 


\section{References:}

[1]Chen X. Analysis on Psychological Factors to Affect the Vocal Stage Performance[J]. Cross-Cultural Communication, 2012, 8(5).

[2]Howard S A. The Effect of Selected Nonmusical Factors on Adjudicators' Ratings of High School Solo Vocal Performances.[J]. Journal of Research in Music Education, 2012, 60(2):166-185.

[3]Lehmann M, Kopiez R. The influence of on-stage behavior on the subjective evaluation of rock guitar performances[J]. Musicae Scientiae, 2013, 17(4):472-494.

[4]Warren R A, Curtis M E. The Actual vs. Predicted Effects of Intonation Accuracy on Vocal Performance Quality[J]. Music Perception, 2015, 33(2):135-146.

[5]White B. Music Drama on the Concert Stage: Voice, Character and Performance in Judith Weir's "The Consolations of Scholarship"[J]. Cambridge Opera Journal, 2000, 12(1):55-79.

[6]Coulter T J. Taking it to the Bridge: Music as Performance Edited by Nicholas Cook and Richard Pettengill (review)[J]. Theatre Journal, 2014, 66(2):314-315.

[7]Avila C, Furnham A, Mcclelland A. The Influence of Distracting Familiar Vocal Music on Cognitive Performance of Introverts and Extraverts.[J]. Psychology of Music, 2012, 40(1):84-93.

[8]Chaffin R, Lemieux A F, Chen C. "It is Different Each Time I Play": Variability in Highly Prepared Musical Performance[J]. Music Perception, 2007, 24(5):455-472.

[9]Beegle A C. A Classroom-Based Study of Small-Group Planned Improvisation With Fifth-Grade Children[J]. Journal of Research in Music Education, 2010, 58(3):219-239.

[10]Cypess R. "Esprimere la voce humana": Connections between Vocal and Instrumental Music by Italian Composers of the Early Seventeenth Century[J]. Journal of Musicology, 2010, 27(2):181-223. 